\title{
An Environmental Impact and Cost Evaluation of Manufacturing System
}

\section{- Application to a heat treatment system -}

\author{
Yohei Hara *, Hiroyuki Ono *
}

\begin{abstract}
Environmental benign manufacturing system has been pursued in manufacturing companies together with the reduction of manufacturing cost, which means the necessity of developing a simultaneous evaluation method of environmental and manufacturing cost. In general, environmental evaluation of the manufacturing system is difficult due to its complexity and peculiarity to each company. In this study, to cope with the problem, a hierarchically structured process flow in manufacturing system is introduced to visualize the manufacturing process. The process flow is composed of unit processes which stand for operations and the data necessary to the evaluation of environmental and cost are put into the lowest lever unit processes. Cost evaluation is carried out by the method of activity based costing. This method simultaneous evaluation of both environmental impact and manufacturing cost is applied to the evaluation of a heat treatment system. The system processes automotive machine parts with the use of either gas soft nitriding or gas carburizing method. In the case of gas soft nitriding the amount of $\mathrm{CO}_{2}$ emission, environmental impact defined by Eco-indicator 95, energy consumption and manufacturing cost per $1 \mathrm{~kg}$ machine parts are $1.63 \mathrm{~kg}, 5.50 \times 10^{-3}, 18.7 \mathrm{MJ}$ and 88.22 yen respectively. On the other hand, the corresponding values of gas carburizing are as follows: $0.655 \mathrm{~kg}, 8.75 \times 10^{-4}, 7.7 \mathrm{MJ}, 55.36 \mathrm{yen}$. As the result, the method of gas carburizing is preferable from the viewpoint of environment and cost.
\end{abstract}

Keywords: Environmental Impact; Manufacturing System; Manufacturing cost.

\section{Introduction}

Since the economic burden of solving global environmental problems is expected to increase for companies, it is necessary for manufacturing companies with significant environmental impacts to review their corporate systems, including reforming the production system and improving production methods [1][2].

In order to, realize a recycling-oriented society, it is important to evaluate the environmental characteristics of industrial products and circulate resources while reducing load

* Chiba Institute of Technology, Chiba, Japan 
and impact. Environmental evaluation of products is required to be evaluated in the life cycle from material production to disposal, and the introduction of life cycle assessment (Life Cycle Assessment: LCA) is essential. For LCA, ISO14040 stipulates a large frame, and many examples of evaluating the environmental impact of products have been reported so far [3][4]. Focusing on the manufacturing stage of LCA products, the process is extremely complex, and standard environmental evaluation methods have not been established. In order to implement environmental measures in the manufacturing industry, it is essential to evaluate the economy, such as manufacturing costs, as well as the environmental impact and impact at the same time.

Evaluation of the economics of the manufacturing sector is generally based on costing criteria. In the traditional costing method based on the costing standards established in 1967, the ratio of manufacturing overhead to the total cost is assumed to be relatively low, and the manufacturing overhead is allocated to the product based on the working time put in by the field worker by product and the usage time by the product of the manufacturing machine. However, in the recent manufacturing process and manufacturing overhead of machinery and equipment has increased relatively due to automation and support for high-mix low-volume production. the ratio of the manufacturing overhead of machinery and equipment has increased relatively from the correspondence to automation and multi-variety low-volume production, and the necessity to allocate this part accurately to the product has become a problem. As a way to solve this problem, the ABC method (Activity- Based Costing) was proposed in the 1980s, and the allocation was refined [5].

In this study, LCA pay attention to the manufacturing stage of LCA [6] which has a hierarchical structure, and propose a method to evaluate the environmental evaluation and the manufacturing cost by $\mathrm{ABC}$ at the same time. We also apply this method to a heat treatment processing system, evaluate it, and confirm its effectiveness. In addition, the environmental impact is evaluated by the unified index of the environmental impact item of eight items. However, in Eco-Indicator95, the weight of global warming was set at 1.14 by introducing the target value of the Kyoto Protocol.

\section{Evaluate Method}

\section{A. Tiering the manufacturing process}

Each stage of the LCA, such as manufacturing, manufacturing (processing and assembly), use, recovery, and disposal of materials, is located at the top level 0 and displays the manufacturing process in a hierarchical structure from level 0 to Manufacturing process level 3 (Figure 1). The upper unit process is represented by a process flow consisting of several lower-level unit processes. Visualize the manufacturing process by creating a process flow in which the process or work is the lowest unit Visualizations process. Assessing the environment and economy. The hierarchical structure is applied as necessary for each stage of manufacturing, use, collection and disposal of materials other than manufacturing. 


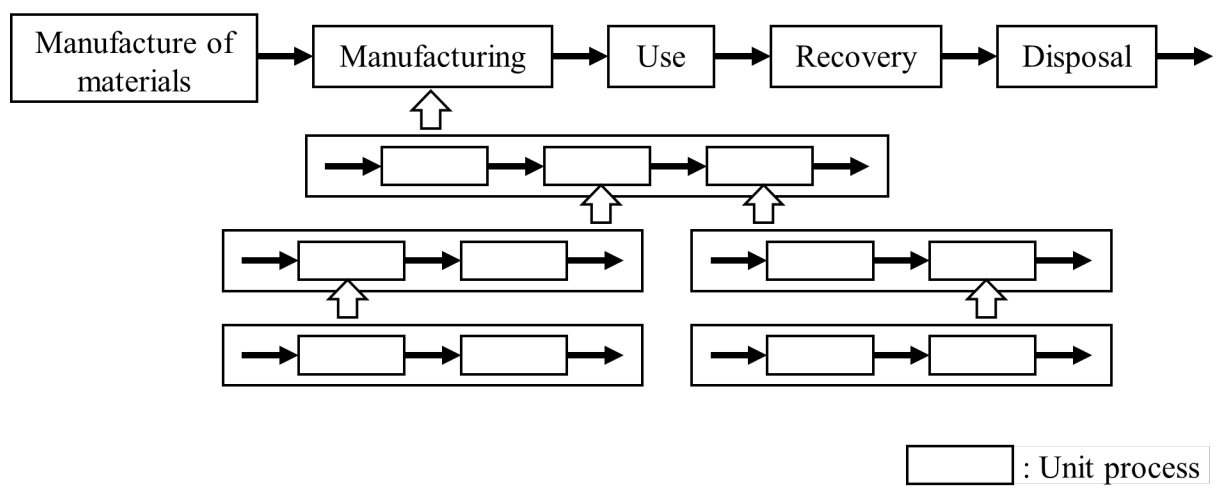

Figure 1: Hierarchical Process Flow

B. Unit process and information entry

It shows the data required to assess the environment and manufacturing costs of the production system. The unit process for entering the match activities that enter the data required to assess manufacturing costs, data necessary for environmental evaluation matches the activity to enter the data necessary for the evaluation of manufacturing costs, and then both are unit processes. I/O data to the unit process is shown in Figure 2.

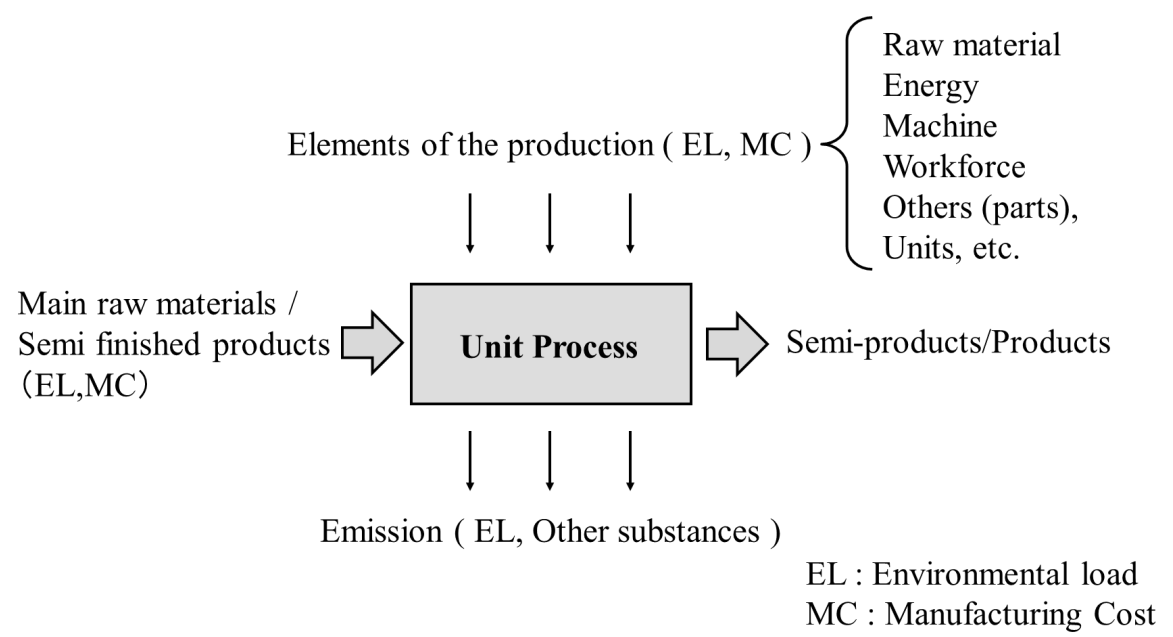

Figure 2: Environmental impact and manufacturing cost I/O data to the unit process

The unit price of the Unit price of production elements and their input main raw materials/semi-products and other production elements and their inputs, emissions (emissions) and their quantities are entered. The input amount of the main raw material / semi-product and the production element is the amount required when the main raw material / semi-product is output one unit from the unit. As a result, it is possible to consider the impact of material yield on environmental impact, impact, and manufacturing costs. Emissions are environmentally hazardous substances of fore grades emitted by the unit process. 


\section{Environmental load and Impact Assessment Data}

The environmental impact associated with the introduction of main raw, materials/semi-products and other production elements was calculated based on the emission units $\left(\mathrm{CO}_{2}\right.$, NOx, Sox, $\left.\mathrm{COD}, \mathrm{BOD}, \mathrm{Cd}\right)$ [7] for the input material. However, the power input energy was estimated based on the environmental impact announced by TEPCO Co., Ltd [8].

The environmental impact of the machines and equipment to be introduced was omitted because the environmental impact divided by each product produced is extremely small.

D. Manufacturing cost assessment data

The manufacturing costs (units: yen) required for evaluation consist of direct manufacturing costs and manufacturing overheads, respectively, material costs, labor costs and expenses. For each cost, a cost driver was set up for each unit process and allocated.

E. Assessment of environment and manufacturing costs

It was evaluated with the following functions for the purpose of evaluating complex manufacturing processes.

(1) Visualization of complex manufacturing processes by hierarchical structure of process flows consisting of unit processes.

(2) Calculate the initial input of the main raw material to the final output of the unit of the process flow consisting of $\mathrm{n}$ unit processes. However, each represents the amount of input and output in the unit process. Based on this, after specifying the input amount of the main raw material to each unit process, the amount of auxiliary raw material required is calculated.

(3) The sum of environmentally hazardous substances in each unit process is calculated, and environmental impact items and environmental impact values are calculated. The environmental impact value is evaluated by the unified index, Eco-Indicator95, using eight environmental impact items. However, the weighting of global warming was set at 1.14 by introducing the target value of the Kyoto Protocol. The input energy and manufacturing costs are also calculated as the sum of each unit process. Visualization of complex manufacturing processes by hierarchical structure of process flows consisting of unit processes.

\section{Application to Heat Treatment Processing Systems}

A large amount of energy is input to the heat treatment processing system, and a large amount of environmental impact is discharged. Therefore, it is necessary to quantitatively evaluate the environmental impact and impact along with manufacturing costs. Here, when gas soft nitride ware and gas carbride ware are applied to the heat treatment processing system of mechanical parts, the manufacturing cost, environmental impact, and impact are evaluated by the method shown in the previous chapter.

\section{A. Heat treatment processing parts}

The machine parts covered are automotive parts of low carbon steel (S35C) (shaft 
gear: $100 \mathrm{~g})$. The weight of the batch processing is $80 \sim 100 \mathrm{~kg}$, and the unit of evaluation is 1 $\mathrm{kg}$.

B. Heat treatment process flow

The process flow with hierarchical structure for the heat treatment processing system is shown in Figure 3. The heat treatment system consists of four units of heat treatment, as shown in Level 1, which delves into the production of Level 0.

(1) Order-to-order process

(2) Processing process

(3) Inspection process

(4) Shipping process

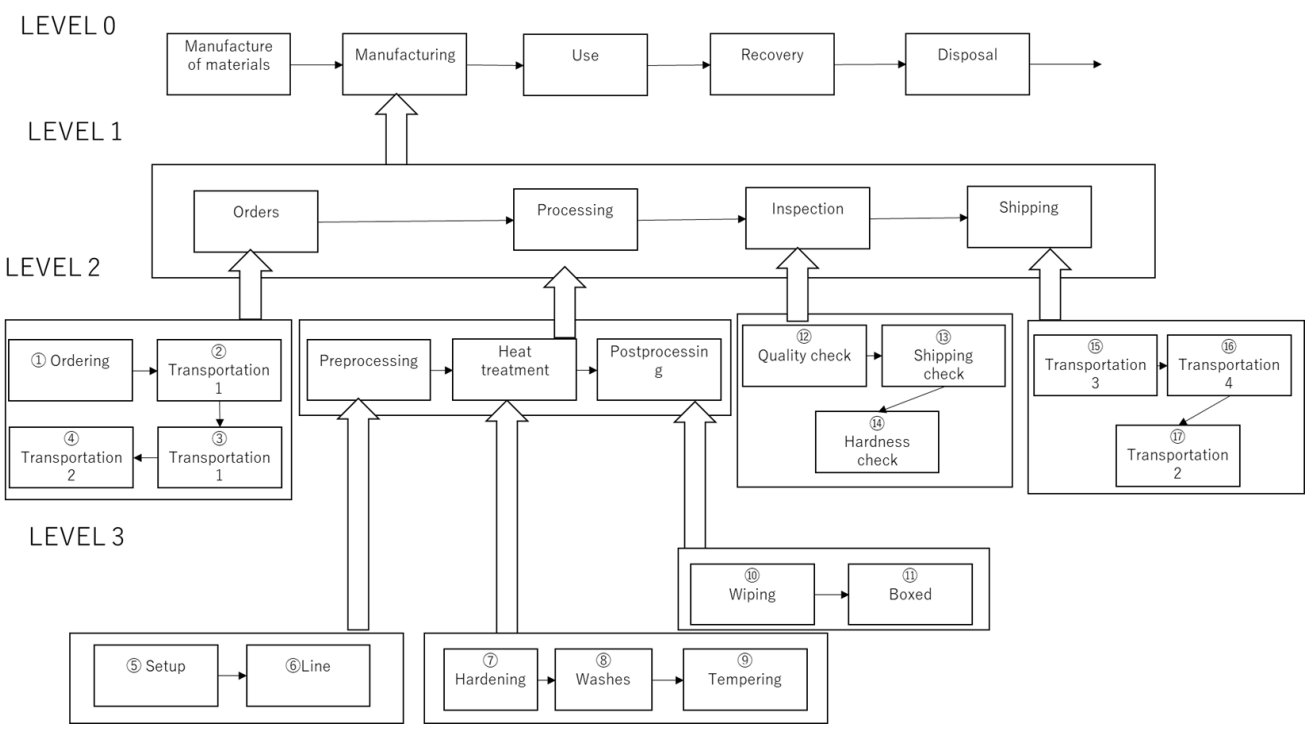

Figure 3: process flow with hierarchical structure for the heat treatment processing system Hierarchical Process Flow

All processes described above (1), (2), (3) and (4) are evaluated. Heat treatment of (2) is gas soft nitride ware and gas erosion ware. The input data necessary for calculating environmental impact and impact are shown in Table 1, and the name, work content, and cost of each unit process are shown in Table 2. The lower unit processes from (1) to (4) were numbered. The labor costs in Table 1 were allocated using the worker's working time. 
Table 1: Input data required for environmental impact and impact (input data required for $1 \mathrm{~kg}$ heat treatment processing)

\begin{tabular}{|c|c|c|c|c|c|c|c|c|c|c|}
\hline $\begin{array}{l}\text { Process } \\
\text { No. } \\
\end{array}$ & Level & $\begin{array}{l}\text { Process } \\
\text { No. }\end{array}$ & $\begin{array}{l}\text { Light oil } \\
(\mathrm{L})\end{array}$ & $\begin{array}{l}\text { Gasoline } \\
(\mathrm{L})\end{array}$ & $\begin{array}{l}\text { Electric power } \\
(\mathrm{MJ})\end{array}$ & Tricre (L ) & $\begin{array}{l}\text { Nitrogen } \\
\left(\mathrm{m}^{3}\right)\end{array}$ & $\begin{array}{l}\text { Methanol } \\
(\mathrm{L})\end{array}$ & $\begin{array}{l}\text { Ammoni } \\
\mathrm{a}(\mathrm{L})\end{array}$ & $\begin{array}{l}\text { Oil } \\
(\mathrm{L})\end{array}$ \\
\hline (1) & 2 & (1) & & & & & & & & \\
\hline (2) & 2 & (2) & $9.12 \times 10^{-3}$ & & & & & & & \\
\hline (3) & 2 & (3) & $9.26 \times 10^{-5}$ & $1.80 \times 10^{-4}$ & & & & & & \\
\hline (4) & 2 & (4) & $9.26 \times 10^{-5}$ & $1.74 \times 10^{-4}$ & & & & & & \\
\hline (5) & 3 & (14) & & & & & & & & \\
\hline (6) & 3 & (15) & & & $3.80 \times 10^{-3}$ & & & & & \\
\hline (7) & 3 & (16) & & & 8.534 & & 0.0195 & 0.292 & 0.00179 & 0.0713 \\
\hline (8) & 3 & (17) & & & $5.21 \times 10^{-1}$ & $4.76 \times 10^{-1}$ & & & & \\
\hline (9) & 3 & (18) & & & 1.83 & & & & & \\
\hline (10) & 3 & (19) & & & $2.99 \times 10^{-3}$ & & & & & \\
\hline (II) & 3 & (201) & & & $2.02 \times 10^{-3}$ & & & & & \\
\hline (12) & 2 & (8) & & & & & & & & \\
\hline (113) & 2 & (9) & & & & & & & & \\
\hline (14) & 2 & (Ii) & & & & & & & & \\
\hline (15) & 2 & (11) & $9.26 \times 10^{-5}$ & $1.80 \times 10^{-4}$ & & & & & & \\
\hline (16) & 2 & (12) & $9.26 \times 10^{-5}$ & $1.74 \times 10^{-4}$ & & & & & & \\
\hline (17) & 2 & (13) & $9.12 \times 10^{-3}$ & & & & & & & \\
\hline
\end{tabular}

Table 2: Work content and cost of each unit process (costofl kg heat treatment) (unit: yen)

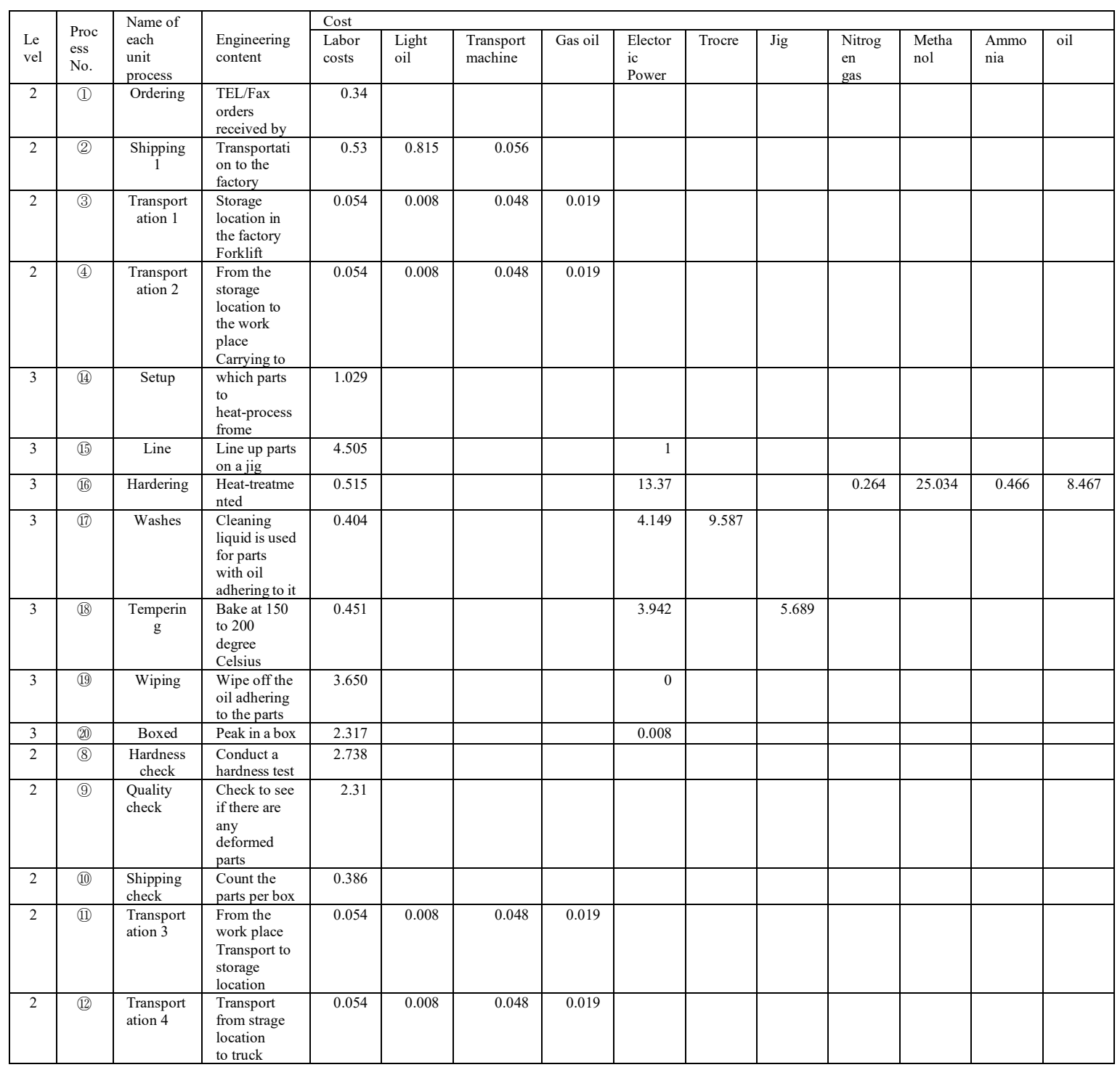




\section{Results and Consideration}

A. Evaluation of gas soft nitride ware

(1) Assessment of environmental impact and impact

When processing $1 \mathrm{~kg}$ of gas machine parts in Table $3, \mathrm{CO}_{2}$ emissions of gas soft nitride ware, energy consumption and environmental impacts were $1.63 \mathrm{~kg}, 18.7 \mathrm{MJ}$ and $5.50 \times 10^{-3}$ (Table 3 ). In addition, the value of acid rain is the largest in environmental influences global warming, nutrientation of lakes, in the order of winter smog.

Environmental impact value of each process of gas soft nitride ware. The cost is shown in Figure 4. The environmental impact of gas soft nitride ware is the value of the put is the highest, and it is in the order of washing and re-baking.

Table 3: Assessment of Environmental Impact and Impact and Energy

\begin{tabular}{|l|r|}
\hline Categry of environmental Impact & Gas soft nitride \\
\hline & Environmental impact \\
\hline Global warming & $6.35 \times 10^{-4}$ \\
\hline Depletion of the ozone layer & 0 \\
\hline Acid rain & $4.54 \times 10^{-3}$ \\
\hline Nutrientization of Lakes and Lakes & $3.28 \times 10^{-4}$ \\
\hline Heavy metals & 0 \\
\hline Carcinogens & 0 \\
\hline Winter Smog & $5.35 \times 10^{-7}$ \\
\hline Summer Smog & 0 \\
\hline Total & $5.50 \times 10^{-3}$ \\
\hline $\mathrm{CO}_{2}(\mathrm{~kg})$ & 1.63 \\
\hline Energy $(\mathrm{MJ})$ & 18.7 \\
\hline
\end{tabular}

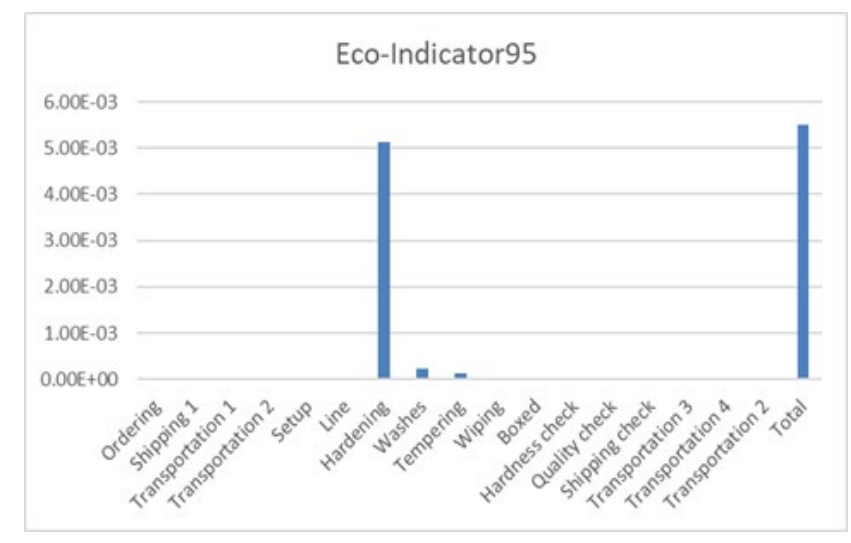

Figure 4: Each Unit Process Assessing the impact of the environment 
(2) Assessing manufacturing costs

The cost of each unit process is shown in Figure 5. The total cost was 88.22 yen per $\mathrm{kg}$ of, parts. In the process, the baking process is the highest at 48.89 yen, followed by cleaning and re-baking.



Figure 5: Production cost of gas soft nitride ware (Yen $/ \mathrm{kg})$

B. Evaluation results of gas-erosion ware

(1) Assessment of environmental impact and impact

The results of the evaluation on the environmental impact and impact of gas erosion ware are shown in Table $4 . \mathrm{CO}_{2}$ emissions and energy consumption and environmental impacts were $6.65 \times 10^{-1} \mathrm{~kg}, 7.70 \mathrm{MJ}$ and $8.75 \times 10^{-4}$, respectively. The influence of acid rain is the oldest in the environmental effects, global warming, nutrientation of lakes, in the order of winter smog.

Table 4: Environmental Impact and Energy of Gas Erosion Ware

\begin{tabular}{|l|r|}
\hline Categry of environmental Impact & Gas erosion grilled \\
\hline & Environmental impact \\
\hline Global warming & $2.59 \times 10^{-4}$ \\
\hline Depletion of the ozone layer & 0 \\
\hline Acid rain & $4.80 \times 10^{-3}$ \\
\hline Nutrientization of Lakes and Lakes & $1.36 \times 10^{-4}$ \\
\hline Heavy metals & 0 \\
\hline Carcinogens & 0 \\
\hline Winter Smog & $2.43 \times 10^{-7}$ \\
\hline Summer Smog & 0 \\
\hline Total & $8.75 \times 10^{-4}$ \\
\hline $\mathrm{CO}_{2}(\mathrm{~kg})$ & 6.65 \\
\hline Energy ( MJ ) & 7.70 \\
\hline
\end{tabular}

Environmental impact value of each step of gas-erosion ware.

The cost is shown in Figure 6. Environmental impact value of the gas erosion ware, the value of the erosion is the largest, it is in the order of re-baking and washing. 


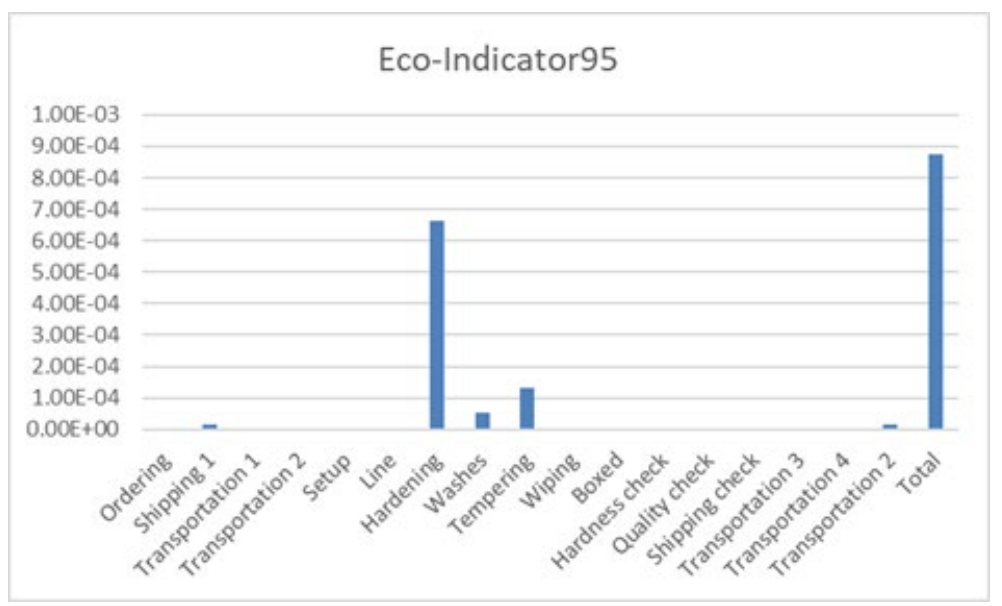

Figure 6: Each unit process assessing the impact of the environment

\section{(2) Cost assessment}

Processing cost per kg by gas-erosion ware is shown in Figure 7. The total cost was 55.36 yen. In the process, the baking process is the highest at 16.86 yen, and the baking and washing are followed by this.

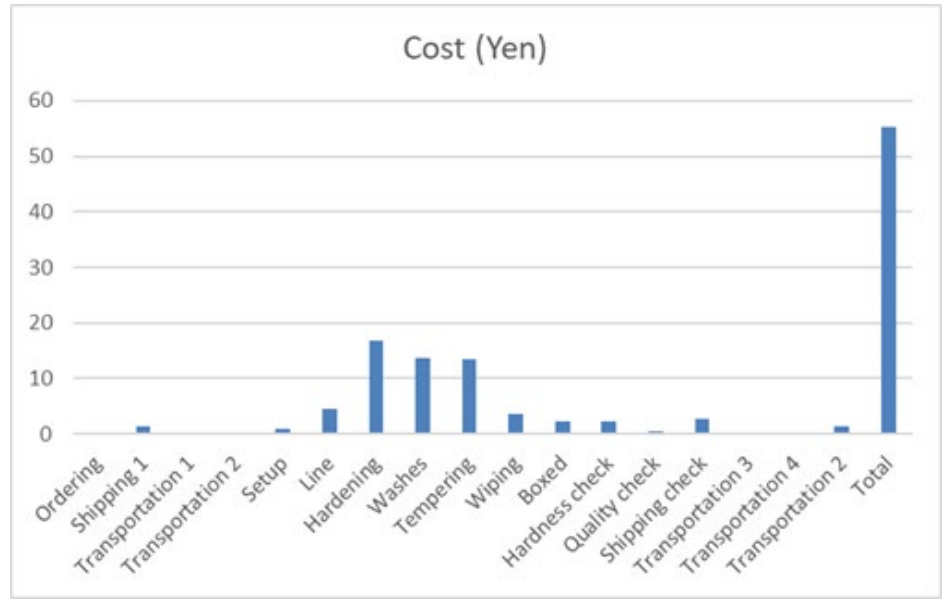

Figure 7: Manufacturing cost of gas erosion ware (Yen/kg)

\section{Comparison of ware in processing}

From Table 3 and 4, the environmental impact value per $\mathrm{kg}$ that occurs in all steps of gas soft nitride ware and gas carbride ware is $5.50 \times 10^{-3}, 8.75 \times 10^{-4}$, and the gas soft nitride ware is 6.3 times. This is due to the extremely high acid rain value of gas soft nitride quenching, and the use of ammonia, nitrogen gas and quench oil is considered to be the cause. On the other hand, for global warming, gas soft nitride ware is only 2.5 times that of gas erosion ware. Both processing methods have a significant environmental impact in the baking process. 
The cost of gas soft nitride ware and gas erosion ware was 88.22 yen and 55.36 yen (Figure 5,6). nitride ware is much longer than gas carbride ware, because the processing time of the erosion is longer, and the cost of electricity, propane gas, and methanol increases. If the performance required after ware is obtained by gas soft nitride ware and gas carbride ware, it was found that the choice of gas erosion ware is effective from both environmental and economic sides.

In addition, in order to consider improvement from the viewpoint of environment and economy, improvement measures are considered for each unit process, and it is possible to select the optimal process after the evaluation as a whole by the method shown in Chapter2.

\section{Conclusion}

As a method of evaluating the environment and cost of the production system, the unit process which is subdivided to the necessary level is visualized by the hierarchical structure, and the evaluation method of the environmental load, the influence, and the cost based on $\mathrm{ABC}$ is proposed.

Specifically applied to heat treatment processing systems, machine parts per $\mathrm{kg}, \mathrm{CO}_{2}$ emissions from gas soft nitride ware are $1.63 \mathrm{k}$, energy consumption is $18.7 \mathrm{MJ}$, the environmental impact value is $5.50 \times 10^{-3}$ and the cost is 88.22 yen, $\mathrm{CO}_{2}$ emissions from gas-erosion ware are $0.655 \mathrm{~kg}$, energy consumption is $7.70 \mathrm{MJ}$, the environmental impact value is $8.75 \times 10^{-4}$ and the cost was quantitatively evaluated at 55.36 yen, this study was able to confirm the effectiveness of the method.

Alover not specifically studied, in this paper, it is also possible to improve the system by focusing on unit processes with high environmental impact based on the results of Figures 4 and 6 and evaluating the environmental impact and cost associated with changes.

\section{References}

[1] Yoshihiro Adachi, Taiya Matsuno, Ichiro Tsuji, and Hiroaki Higuchi, Ring System Engineering, University of Tokyo Press, 2004.

[2] Ministry of the Environment, General Environment Policy Bureau, Environmental White Book, 2004.

[3] Tetsuo Nakayama, "Life Cycle Aces in Japan Development of Smento Methods and Trends in International Standardization", Journal of the Society of Nergy, Vol77, No10, 1998, PP.934-940.

[4] LCA Introductory Editorial Committee, Introduction to LCA Practice, Industry Sakai Management Association, 1998.

[5] Mark Cheap, "The Eco-indicator 95 Final Report", PRe Consultants, 1996.

[6] Bengt Steen,"EPS-Default Valuation of Environmental Impacts from Emission and Use of Resources Version 1996”, CPM, 1996.

[7] Atsushi Terazono, "Life Cycle Assessment Impak Weighting of Environmental Impacts in Assessment Law”, Safety Engineering, Vol35, 1996, pp. 399-409. 
[8] Tokuhiro Ijima and Kaoru Inaba, Impact of Life Cycle Environment Evaluation LIME-LCA, Environmental Accounting, Review for Environmental Efficiency Methods and Databases, Industrial Management Association, 2005.

[9] Takeo Yoshikawa, Japan-type ABC Management, Productivity Publishing, 1997.

[10] Hiroyuki Ono, Torio Sano, Yasushi Nishizaki, Tsutomu Uda, Shuichiro Ono and Yutaka Shirai:, "Environmental Evaluation of Manufacturing Processes in the Assembly Industry Use of CAD/CAM Data - ", Journal of the Japan Society of Management Engineering, Vol. 59, No1, 2008, pp.68- 73.

[11] LCA Japan Forum; http://www.jemai.or.jp/lcaforum/.

[12] TEPCO; http://www.tepco.co.jp/eco/earth/jyourei/toukyo-j.html. 